\title{
Socio-Biological Determinants of Low Birth Weight: A Community based study from rural field practice area of Medical College, Kolkata, West Bengal (India)
}

\author{
Dr Nirmalya Manna ${ }^{1}$, Dr. Jhuma Sarkar ${ }^{1}$, Dr. Baijayanti Baur ${ }^{1}$, \\ Dr. Gandhari Basu ${ }^{2}$, Dr. Lina Bandyopadhyay ${ }^{3}$ \\ ${ }^{1}$ Department of Community Medicine, Medical College, Kolkata, India \\ ${ }^{2}$ Department of Community Medicine, College of Medicine \& J.N.M. Hospital Kalyani, India \\ ${ }^{3}$ All India Institute of Hygiene \& Public Health, Kolkata, India
}

\begin{abstract}
Birth weight is the single most important criteria for determining the neonatal and infant survival. Low Birth Weight is the result of complex interplay of various social and reproductive health factors. A cross-sectional community based retrospective study was carried out in rural West Bengal among 540 birth episodes. Proportion of low birth weight infants were found significantly more among mothers elderly \& teenaged, less educated, addicted to tobacco, Multipara and primipara, received less antenatal care, female infants, delivered at home, short stature, anaemic and had obstetric complications. Focused attention to reduce low birth weight babies, community specific strategies such as improving awareness of the community and utilization of existing maternal health services is essential.
\end{abstract}

Keywords: Biological factors, Low Birth Weight, Rural Community, Social factors.

\section{INTRODUCTION}

Low birth weight is a challenging multifaceted public health problem because it is associated with increased risk of morbidity and mortality of infants. There is no indicator in human biology, which tells us so much about the past events and the future trajectory of life, as the weight of infant at birth. Conditioned by the Health \& Nutritional status of the mother, the percentages of infants born with Low Birth Weight closely reflects the Health status of the communities in which they are born. For which $34^{\text {th }}$ World Health Assembly in 1981 included LBW as one of the global indicators for monitoring health of the community. Birth weight is a reliable and sensitive indicator for predicting the immediate and long term outcome of a newborn. The low birth weight new borns are four times more likely to die from common childhood diseases in the first year of life, than their normal counterpart. The public health significance of low birth weight may be ascribed to numerous factors, its high incidence, increased risk of perinatal and infant mortality, morbidity and disabilities, its association with mental retardation, the very high cost of specialized institutional care and intensive care units, and its association with socio-economic underdevelopment. There is also emerging evidence that low birth weight neonates are more prone to diabetes mellitus, hypertension and coronary artery disease in later life. Worldwide, the magnitude of LBW problem (defined as infants weighing less than $2500 \mathrm{gm}$. at birth) varies widely from country to country, from $4.5 \%$ in most developed countries to almost $50 \%$ in some of the least developed countries. It is estimated that worldwide $15.5 \%$ of all Live births per year are Low Birth Weight and more than 95\% LBW infants are born in developing countries,72\% in Asia with striking regional variations $27 \%$ in Southern Asia,6\% in Eastern Asia except Thailand (36\%). In India the proportion of baby weighing less than $2.5 \mathrm{~kg}$ is higher in rural areas (28\%) than in urban areas (21\%). Birth weight is determined by the complex interplay of numerous factors like genetic, reproductive, obstetric, social and environmental. But the etiology of low birth weight is maximally related to maternal factors like early marriage with teenage pregnancies, frequent $\&$ too many pregnancies, maternal malnutrition, anemia and infections. Poor health and education of female children along with low status and empowerment of women in the society are the important contributory factors. The natural history of low birth weight babies usually begins with the girl's childhood malnutrition. A girl, who is malnourished during early childhood and puberty becomes a short stature women and delivers small baby. The best opportunity of breaking this cycle of "deprivation" is improving the nutritional status of children and adolescents, with greater equity, supported by care for the mothers. In spite of huge advances in the medical science of pregnancy and delivery, the proportion of LBW births has changed little in the world during the past 30 years due to failure to tackle the root causes like too early, too close, too many pregnancies, too little food, too much work, lack of antenatal care including iron-folic acid supplementation etc; are still unsatisfactory. ${ }^{1-13}$ Both community and institution based studies are needed to find out the lacunae of occurrence of low birth weight babies, so that effective strategies which are relevant to the local conditions can be adopted for 
prevention of low birth weight. With the above background, the present retrospective epidemiological investigation was conducted in a rural community of West Bengal with the following objective:

To find out the proportion of low birth weight babies along with relationship between birth weights and mother's socio-economic and health parameters.

\section{METHODOLOGY}

A retrospective community based cross-sectional study was carried out in the Tarakeswar block, at Hooghly district, West Bengal, the rural field practice area of Medical College, Kolkata, India, in the year 2010. Tarakeswar is situated around 50 Kilometer from Kolkata catering population of 1,75,523 (Census India-2001). Considering the prevalence of low birth weight baby as $28 \%$ in India's rural $\operatorname{area}^{2}, 95 \%$ confidence limit and allowable error 10\%, the sample size was calculated using Epi Info version 3.5.1 and it became 982 . Considering the feasibility of the study it was decided that $50 \%$ of the sample i.e. 491 sample will be covered for the purpose of the present study. Adding 10\% non- response, the total number came out to be 540 . Mothers who have delivered singleton babies in the last one year were considered as study population. The list of all mothers who delivered in last one year was prepared from the ECCR (eligible couple and child register) and it was 2229 and they constituted the study population. By using simple random sampling technique, total number of sample (540) was selected from the list of 2229 mothers with name and address. Exclusion criteria were, mothers who were chronically ill, unable to show relevant documents or doors closed. In these cases the next eligible mother was interviewed. After taking informed verbal consent, mothers were interviewed by house-tohouse visit, using a pre designed and pre-tested semi-structured proforma. First part of the proforma included socio-demographic and personal characteristics like age, religion, level of education, occupation, type of family, per capita income, tobacco addiction. Socio-economic status was calculated by using Prasad's scale ${ }^{14}$, which is commonly used in India. Second part of proforma contained questions about birth weight and pregnancy related and mothers' health related variables. Weight of the baby less than 2500 grams irrespective of the period of gestation was considered as low birth weight. Secondary data were obtained from previous ante-natal records, outpatient department tickets, birth certificates, and labour room discharge certificates. Collected data were compiled in Microsoft Excel sheet, analyzed using Epi Info version 3.5.1 and SPSS version 17 statistical software. Data were analysed in two levels, first by proportion and $\chi^{2}$ test and finally by binary logistic regression model. In regression analyses wald's test was used for the significance of the risk factors for LBW. LBW was considered as dependant variable and was categorized into two groups: $<2.5 \mathrm{~kg}$. \& $\geq 2.5 \mathrm{~kg}$. and other variables were entered into the model as independent variables. $\mathrm{P}$ value $<0.05$ was considered as significant.

\section{RESULTS}

This study showed that among the 540 birth events we interviewed 167 infants (30.9\%) were low birth weight (167/540) babies. It was evident from Table 1 that proportion of low birth weight babies were more than their normal counterpart in both the teenage mothers aged $\leq 19$ yrs. (lbw-54.1\%,nbw-45.9\%) and elderly mothers aged $\geq 40$ yrs. (lbw- $54.4 \%, 45.5 \%$ ). Whereas mothers who delivered their babies in their $20-39$ years age had more proportion of normal birth weight babies, nearly three-fourth. This relation of age of the mother and proportion of low birth weight baby was also statistically significant $(\mathrm{p}=.0001)$. Proportion of low birth weight babies were less for Hindu mothers (24.5\%) compared to mothers belonged to Muslim(54.6\%) and other religion $(46.6 \%)$ and this was also statistically significant $(\mathrm{p}=0.0001)$. Maximum proportion of low birth weight babies were found among illiterate mothers $(41.3 \%)$ followed by mothers with primary education $(28.1 \%)$. As the education of the mother increased, the prevalence of low birth weight also significantly $(\mathrm{p}=0.001)$ decreased (secondary-25.5\%, higher secondary-22.1\%, graduate\& above-15.6\%).Housewives delivered maximum (42.5\%) proportion of $\mathrm{lbw}$ babies greater than agricultural worker(26.2\%), daily labourer $(26.8 \%)$.and this was also significant ( $\mathrm{p}-=.0004)$. Mothers came from nuclear family $(35.2 \%)$ delivered significantly $(\mathrm{p}=.03)$ more low birth weight babies than mothers from joint family $(26.6 \%)$. Low birth weight babies were found in lower proportion in lower income categories (class V-27.5\%,class IV-24.1\%) than higher classes (class I-32.1\%,II-34.7\%,III$31.4 \%$ ) though it was not significant $(\mathrm{p}=0.55)$. Mothers who were addicted to tobacco (any form) had significantly $(\mathrm{p}=.0001)$ more proportion of low birth weight babies $(54.4 \%)$ than non addicted mothers. Association of birth weight with pregnancy related variables were depicted in Table 2. Low birth weight babies were maximum $(54.8 \%)$ for mothers had 3 or more children followed by primipara mothers $(24.3 \%)$ which was also statistically significant $(\mathrm{p}=.000)$. Significantly $(\mathrm{p}=.000)$ least proportion of low birth weight babies (15.1\%)were found among mothers who came early ( $\leq 12$ weeks) for first visit during antenatal period, which rose to $48.4 \%$ for mothers came after 16 weeks. When the number of Antenatal visits were $\geq 4$ low birth weight prevalence was less $(25 \%)$ than no. of visits $<4(36.3 \%)$ ( $\mathrm{p}=.004)$. During pregnancy those mothers who had not taken no extra diet, $40.6 \%$ delivered low birth weight babies but this proportion was $14.8 \%$ when the mothers took both extra amount of food and one extra diet which was also significant $(\mathrm{p}=0.0001)$.Maximum proportion 
of lbw babies were found among mothers who had daily sleep and rest $<8$ hours(45.6\%), but this came down to $22.8 \%$ when the sleep \& rest was $\geq 10$ hours. Low birth weight babies were more who had regular bathing or $\operatorname{not}(33.7 \%$ vs. $16.8 \%)$ which was also significant $(\mathrm{p}=.001)$ and had regular brushing teeth or $\operatorname{not}(31.7 \%$ vs. $21.8 \%)$. Mothers who consumed $\geq 100$ iron folic acid tablets during their pregnancies delivered less $(21.3 \%)$ lbw babies $(\mathrm{p}=0.0001)$ than mothers consumed less than 100 iron folic acid tablets $(37.8 \%)$. Proportion of lbw was more among mothers who had not taken TT injection during pregnancy( Nil-36.5\%,.TT $-29.9 \%, \mathrm{TT}_{2}-$ $28.9 \%)$ though not significant $(\mathrm{p}=.33)$. Female low birth weight babies were significantly $(\mathrm{p}=0.04)$ more $(34.7 \%)$ than their male counterpart $(26.7 \%)$. Significantly $(\mathrm{p}=0.0001)$ more lbw babies were found among mothers delivered in home(59.2\%) than institutional deliveries(19.8\%). Table 3 showed relation of birthweight and mothers' health conditions. It showed that 39.5\% mothers with short height $(<145 \mathrm{~cm}$.) had lbw babies which was $23.9 \%$ for mothers with height $\geq 145 \mathrm{~cm}(\mathrm{p}=0.0001)$. Prevalence of lbw babies was $41.3 \%$ for mothers who showed documentary evidence of infection( $\mathrm{p}=0.01)$. Mothers with anaemia during pregnancy had significantly $(\mathrm{p}=.0001)$ more $\mathrm{lbw}$ babies (45.4\% vs.22.6\%).Hypertensive mothers delivered less lbw babies $(24.4 \%)$ than normotensive mothers $(31.5 \%)$ but it was not significant $(\mathrm{p}=.30)$.Complications during pregnancy resulted in significantly $(\mathrm{p}=0.01)$ more proportion of lbw babies $(40 \%$ vs.28.4\%). Association between Low Birth Weight babies (outcome variable) and different predictor variables such age, socio-economic factors, obstetric factors like parity, components of Antenatal care and maternal health factors were further analyzed by binary logistic regression, findings of which were seen in Table 4. Most of the predictors variables which were considered for this study were found to be significant for occurrence of low birth weight babies except socio-economic status, regular bathing or brushing, receiving tetanus toxoid or not and presence of hypertension during pregnancy.

\section{DISCUSSION}

Globally birth weight has been accepted as single most important determinant of future chances of survival, healthy growth, freedom from morbidities \& mortalities of infants. LBW is a widely used indicator of new-born health. Factors associated with LBW are considered as determinants or predictors and their presence in a particular woman indicates an increased chance of bearing a LBW infant. This retrospective community based study presents the report of 540 birth episodes from a rural area of West Bengal. Among them nearly one third babies were low weight $(<2.5 \mathrm{~kg}$.), which was in concordant with another study in the Puruliya district of West Bengal $(31.3 \%){ }^{3}$ The study conducted in different parts of India (South India,Vellore-11.8\%,North India,Dehradun-23.8\%) and abroad (Nepal-11.9\%,Iran-5.2\%,Vietnam-7.9-12.5\%) showed lower proportion of lbw babies than our study. ${ }^{15-19}$ Reasons might be, different study areas \& study designs, influence of different risk factors were different, health service utilizations might also be different. This study showed that significantly both teenage and elderly mothers had more lbw babies. Probable reasons for younger aged mothers were their low awareness or no experience along with poor nutritional status of the adolescent girls with underdeveloped reproductive organs. For elderly mothers it might be due to increased parity with less spacing. Similar to our study, different other studies also showed similar type of results, K.S.Negi \& others in Dehradun India, ${ }^{16}$ Sareer BadShah \& others in their study in Peshwar ${ }^{20}$ and Hirve SS et al in Pune,India. ${ }^{21}$ But the study in Wardha, Maharashtra by Kiran Anand \& others found no significant relation with age of the mother and birth weight. ${ }^{22}$ Our study showed Muslim mothers had more lbw babies might be due to some cultural factors might have played some negative birth effects and it was in contrast to the findings shown by Mavalankar DV et all in Ahmedabad, India where they found Muslim women were at much lower risk of lbw babies than Hindu mothers. ${ }^{23}$ Similar to other studies, this study also found more proportion lbw were among illiterate and primarily educated mothers. ${ }^{3,21,24,25}$ Reason cited behind this might be, lower level education might have associated with lower health awareness and health seeking behavior of the mothers. Contrast to the findings of other study, ${ }^{24}$ we found lbw babies were more among housewives than agricultural worker or labourer, which might be explained by lower status of the women in our society. Mothers of joint family had less lbw infants might be due to they had received more care or daily activities might have shared. Surprisingly this study showed more proportion of low birth weight babies among higher income categories in contrast to other study findings. ${ }^{21.22 .25}$ Reason of which could not be explained. This study showed that tobacco addicts had more lbw babies which was consistent with other studies. ${ }^{3,24}$ In this study mothers had 3 or more children had maximum proportion of Low Birth Weight babies, might be due to less spacing between births. Second largest proportion were among primipara mothers. Whereas a number of studies showed primipara mothers had maximum lbw babies. ${ }^{1619,22,23,24}$ Similar to other studies this study also found mothers with early registration $(\leq 12$ wks.),no.of antenatal visits $\geq 4$, consumed extra diet $\&$ extra meal and Iron $\&$ Folic acid tablets $\geq 100$, daily sleep $\&$ rest $\geq 10$ hrs., taken 2 doses of Tetanus Toxoid, Institutional delivery had significantly lesser proportion of lbw babies. $^{3,15,16,19,21,23,24}$ We found that girls were more likely to be LBW infants than boys is in accordance with other study. ${ }^{21}$ Mothers had regular bathing or brushing had more lbw babies, reason of which could not be explained. Our study showed that short statured mothers (Ht.<145 cm.), anaemic mothers, had documented evidences of infection and had complications during pregnancy or delivery had significantly more lbw babies. 
The findings were in agreement with other studies. ${ }^{20,21,24,26,27}$ We observed lesser proportion of lbw babies among hypertensive mothers which was contrary to the findings showed in other studies. ${ }^{23,24,25}$ We could not explain this findings because scientifically it is natural that pregnancy induced hypertension resulted reduced placental perfusion thereby increased chance of lbw babies. This study was further analysed by binary logistic regression, findings of which supported that most of the predictor variables we studied significantly played the role of determinants of Low Birth Weight babies except Socio-Economic status, daily bathing or brushing, taken Tetanus Toxoid and presence of hypertension during pregnancy.

There were some limitations in our study. The International definition of LBW was not used. Some other variables like weight of the mother, birth spacing could not be searched for. Despite this fact this community based retrospective study provided data on several risk factors which are modifiable.

\section{CONCLUSION}

Well known social, reproductive and health related determinants of low birth weight were quite prevalent in this community as revealed by our study, majority of which could be prevented or modified. Therefore some strategies addressing improvement of literacy level of the mothers thereby increasing utilization of the existing maternal health services and making sure that mothers at greater risk of delivering LBW babies receive appropriate care, may provide some opportunity to reduce low birth weight babies in this rural area of West Bengal, India.

Table 1: Association between birth weight and mothers socio-demographic variables $(\mathrm{n}=540)$

\begin{tabular}{|c|c|c|c|}
\hline Variables & $\begin{array}{c}\text { Low birth weight } \\
(\mathrm{n}=167) \\
\text { Number }(\%)\end{array}$ & $\begin{array}{l}\text { Normal birth weight (n } \\
=373) \text { Number }(\%)\end{array}$ & Significance \\
\hline \multicolumn{4}{|l|}{ Age of mother in years } \\
\hline$\leq 19$ & $33(54.1)$ & $28(45.9)$ & \multirow{4}{*}{$\begin{array}{c}\chi^{2}=21.04 \\
d f=3 \\
p=0.0001\end{array}$} \\
\hline $20-29$ & $69(27.7)$ & $180(72.3)$ & \\
\hline $30-39$ & $59(26.9)$ & $160(73.1)$ & \\
\hline$\geq 40$ & $6(54.4)$ & $5(45.5)$ & \\
\hline \multicolumn{4}{|l|}{ Religion } \\
\hline Hindu & $92(24.5)$ & $283(75.5)$ & \multirow{3}{*}{$\begin{array}{c}\chi^{2}=23.49 \\
d f=2 \\
p=0.0001\end{array}$} \\
\hline Muslim & $68(45.4)$ & $82(54.6)$ & \\
\hline Others & $7(46.6)$ & $8(53.4)$ & \\
\hline \multicolumn{4}{|l|}{ Education } \\
\hline Illiterate & $83(41.3)$ & $118(58.7)$ & \multirow{5}{*}{$\begin{array}{c}\chi^{2}=18.32 \\
\text { df }=4 \\
p=0.0010\end{array}$} \\
\hline Primary & $36(28.1)$ & $92(71.9)$ & \\
\hline Secondary & $26(25.5)$ & $76(74.5)$ & \\
\hline Higher secondary & $17(22.1)$ & $60(77.9)$ & \\
\hline Graduate\&above & $5(15.6)$ & $27(84.4)$ & \\
\hline \multicolumn{4}{|l|}{ Occupation } \\
\hline House Wife & $77(42.5)$ & $104(57.5)$ & \multirow{5}{*}{$\begin{array}{c}\chi^{2}=20.33 \\
d f=4 \\
p=0.0004\end{array}$} \\
\hline Agricultural Worker & $33(26.2)$ & $93(73.8)$ & \\
\hline Daily Labourer & $36(26.8)$ & $98(73.2)$ & \\
\hline $\begin{array}{l}\text { Service } \\
\text { Teacher }\end{array}$ & $17(26.1)$ & $48(73.9)$ & \\
\hline teacner & $4(11.7)$ & $30(88.3)$ & \\
\hline \multicolumn{3}{|l|}{ Type of Family } & \multirow{3}{*}{$\begin{array}{c}\chi 2=4.46 \\
d f=1 \\
p=0.0311\end{array}$} \\
\hline Nuclear & $96(35.2)$ & $177(64.8)$ & \\
\hline Joint & $71(26.6)$ & $196(73.4)$ & \\
\hline \multicolumn{4}{|l|}{ Socio-economic status } \\
\hline Class - I & $63(32.1)$ & $133(67.9)$ & \multirow{5}{*}{$\begin{array}{c}\chi^{2}=3.00 \\
d f=4 \\
p=0.5570\end{array}$} \\
\hline Class - II & $41(34.7)$ & $77(65.3)$ & \\
\hline Class - III & $28(31.4)$ & $61(68.6)$ & \\
\hline Class - IV & $19(24.1)$ & $60(75.9)$ & \\
\hline Class - V & $16(27.5)$ & $42(72.5)$ & \\
\hline \multicolumn{3}{|l|}{ Addiction to tobacco } & \multirow{3}{*}{$\begin{array}{c}\chi^{2}=69.91 \\
d f=1 \\
p=0.0001\end{array}$} \\
\hline No addiction & $69(19.2)$ & $291(80.8)$ & \\
\hline Addicted to tobacco & $98(54.4)$ & $82(45.6)$ & \\
\hline \multicolumn{4}{|c|}{ Table 2: Association between birth weight and pregnancy related variables $(\mathrm{n}=540)$} \\
\hline Variables & $\begin{array}{c}\text { Low } \\
\text { birth weight }\end{array}$ & $\begin{array}{c}\text { Normal } \\
\text { birth weight }\end{array}$ & Significance \\
\hline
\end{tabular}




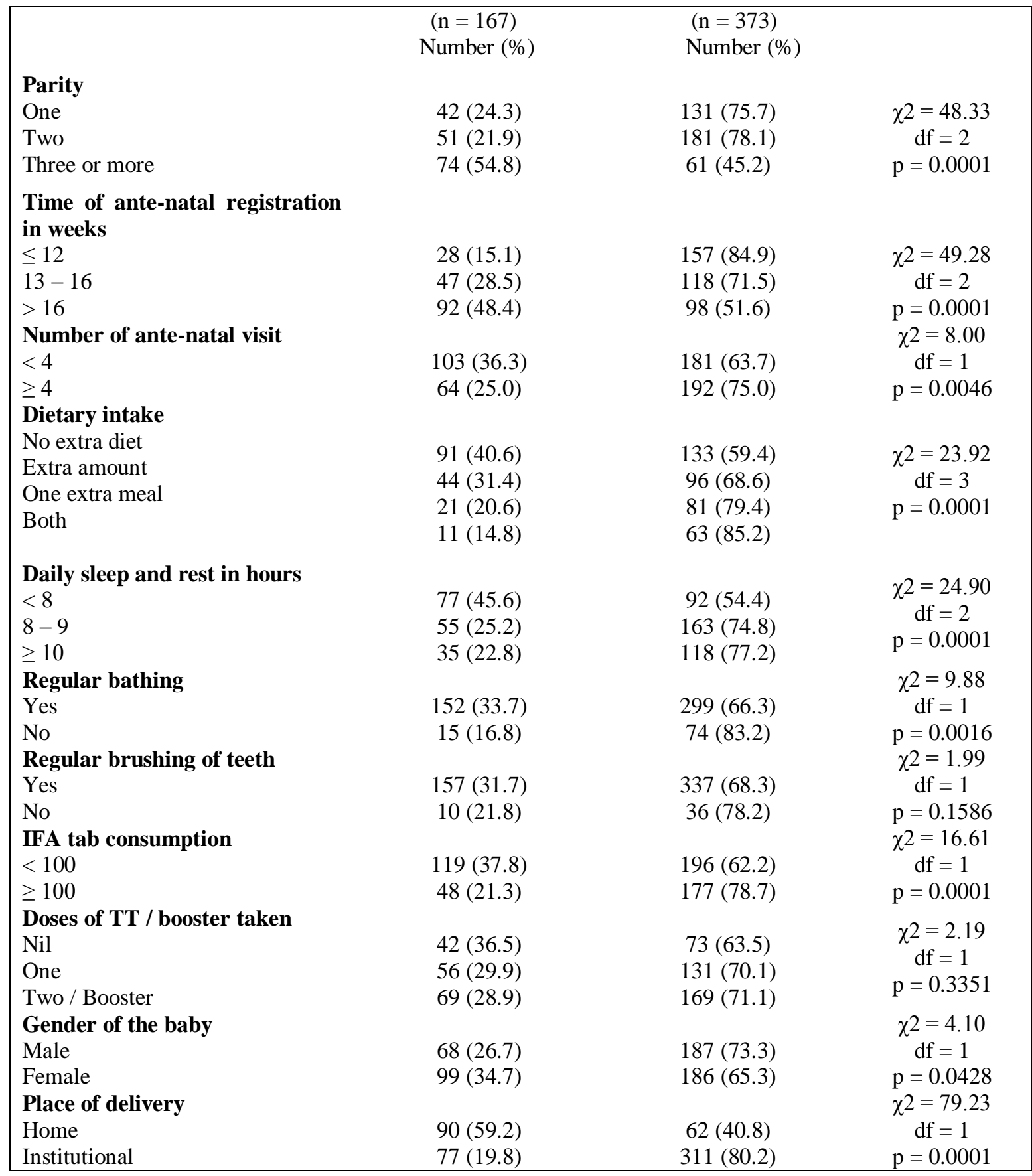

Table 3: Association between birth weight and mothers health related variables $(n=540)$

\begin{tabular}{|lccc}
\hline Variables & $\begin{array}{c}\text { Low birth weight } \\
(\mathrm{n}=167) \\
\text { Number }(\%)\end{array}$ & $\begin{array}{c}\text { Normal birth weight }(\mathrm{n} \\
=373) \text { Number }(\%)\end{array}$ & Significance \\
$\begin{array}{l}\text { Height of mother }(\mathbf{I n ~ c m}) \\
<145\end{array}$ & $96(39.5)$ & $147(60.5)$ & $\chi^{2}=15.23$ \\
$\geq 145$ & $71(23.9)$ & $226(70.1)$ & $\mathrm{df}=1$ \\
$\begin{array}{l}\text { Documented evidence of } \\
\text { infection during pregnancy }\end{array}$ & & & $\mathrm{p}=0001$ \\
$\begin{array}{l}\text { Yes } \\
\text { No }\end{array}$ & $43(41.3)$ & $61(58.7)$ & $\chi 2=6.55$ \\
$\begin{array}{l}\text { Diagnosed anemia during } \\
\text { pregnancy }\end{array}$ & $124(28.4)$ & $312(71.6)$ & $\mathrm{df}=1$ \\
Yes & & & $\mathrm{p}=0.0105$ \\
& $89(45.4)$ & $107(54.6)$ & $\chi 2=30.21$ \\
\hline
\end{tabular}




\begin{tabular}{|lccc|}
\hline $\begin{array}{l}\text { No } \\
\text { Diagnosed hypertension } \\
\text { during pregnancy }\end{array}$ & $78(22.6)$ & $266(77.4)$ & $\mathrm{p}=0.0001$ \\
$\begin{array}{l}\text { Yes } \\
\text { No }\end{array}$ & $12(24.4)$ & $37(75.6)$ & $\chi 2=1.05$ \\
$\begin{array}{l}\text { Documented evidence of } \\
\text { complications during } \\
\text { pregnancy }\end{array}$ & $155(31.5)$ & $336(68.5)$ & $\mathrm{df}=1$ \\
$\begin{array}{l}\text { Yes } \\
\text { No }\end{array}$ & & & 0.3066 \\
\end{tabular}

Table 4. Association between birth weight and risk factors by binary logistic regression

\begin{tabular}{|c|c|c|c|c|c|c|}
\hline Predictor Variable & B & S.E. & Wald & df & $\mathrm{P}$ value & $\operatorname{Exp}(\mathrm{B}) / \mathrm{OR}$ \\
\hline Age & 1.258 & 0.495 & 6.457 & 1 & 0.003 & 0.373 \\
\hline Religion & 1.179 & 0.713 & 2.735 & 1 & 0.002 & 0.394 \\
\hline Education & -0.986 & 0.568 & 3.013 & 1 & 0.006 & 0.052 \\
\hline Occupation & -0.933 & 0.527 & 3.126 & 1 & 0.043 & 2.262 \\
\hline Type of family & -2.955 & 1.187 & 6.192 & 1 & 0.024 & 0.037 \\
\hline Socio-economic status & -0.079 & 0.026 & 9.043 & 1 & 0.119 & 0.842 \\
\hline Tobacco addiction & -1.575 & 0.499 & 9.978 & 1 & 0.048 & 0.388 \\
\hline Parity & 1.858 & 0.675 & 7.587 & 1 & 0.033 & 0.989 \\
\hline Time of registration & -0.325 & 0.417 & 0.609 & 1 & 0.017 & 0.924 \\
\hline Number of visit & -0.818 & 0.708 & 1.334 & 1 & 0.013 & 0.207 \\
\hline Dietary pattern & 0.816 & 0.467 & 3.051 & 1 & 0.049 & 6.414 \\
\hline Sleep and rest & 0.357 & 1.156 & 0.632 & 1 & 0.000 & 2722 \\
\hline Regular bathing & 0.442 & 0.367 & 1.913 & 1 & 0.784 & 0.441 \\
\hline Regular brushing & -0.947 & 0.736 & 1.653 & 1 & 0.199 & 3.517 \\
\hline IFA tab consumption & -0.011 & 0.384 & 0.001 & 1 & 0.043 & 3.253 \\
\hline TT Injection & 0.329 & 0.418 & 2.423 & 1 & 0.723 & 0.841 \\
\hline Gender of baby & -3.294 & 0.889 & 13.731 & 1 & 0.015 & 3.912 \\
\hline Place of delivery & -0.172 & 0.626 & 0.075 & 1 & 0.029 & 2.694 \\
\hline Height of mother & 1.546 & 0.521 & 8.811 & 1 & 0.003 & 4.692 \\
\hline Evidence of Infection & 1.719 & 0.482 & 12.711 & 1 & 0.001 & 5.579 \\
\hline Evidence of complication & 1.289 & 0.318 & 4.016 & 1 & 0.036 & 0.119 \\
\hline Anemia & 3.876 & 0.537 & 52.042 & 1 & 0.009 & 8.232 \\
\hline Hypertension & 3.229 & 0.337 & 10.981 & 1 & 0.259 & 1.768 \\
\hline Constant & 9.147 & 4.709 & 2.119 & 1 & 0.173 & 1017.12 \\
\hline
\end{tabular}

\section{REFERENCES}

[1] H.Phung ,A. Bauman,T.V..Nguyen, L.Young, M. Tran ,K. Hillman. Risk factors for low birth weight in a socio-economically disadvantaged population: Parity, marital status, ethnicity and cigarette smoking. European Journal of Epidemiology 18(3):235-43.

[2] Park K. Maternal and child health in 'Text book of Preventive and Social Medicine'. Jabalpur, India, 20 ${ }^{\text {th }}$ edition Banarasidas Bhanot 2009: 460. 
[3] R. Biswas, A. Dasgupta, R.N.Sinha, R.N.Chaudhury. An Epidemiological study of Low Birth Weight Newborns in the district of Puruliya, West Benngal. Indian J Public Health Apr-Jun 2008;52(2):65-71.

[4] UNICEF (2009), State of world's children, 2009.

[5] Wardlaw T, Blane A, Ahman E. Country regional and global estimate. New York; United Nations' Children Emergency Fund and WHO;2004.

[6] K. P.Stillerman, D.R.Mattison, L.C.Giudice, T.J.Woodruff. "Environmental exposures and adverse pregnancy outcomes: a review of the science." Reproductive Sciences 2008, 15(7):631-50.

[7] V. S. Dogra, S Bhatt. "Intrauterine growth retardation".2005.[accessed online on http:// emedicine.medscape.com larticlel404098].

[8] Roudbari M, Yaghmaei M, Soheili M. Prevalence and risk factors of low birth weight infants in Zahedan, Islamic Republic of Iran. East Mediterr Health J 2007, 13:838-45.

[9] Watson Jone D, Weiss H A, Changalucha J M, Todd J, Gumoduka B, Bulmer J et al. Adverse birth outcomes in United Republic of Tanjania-impact and prevention of maternal risk factors. Bull World Health Organ 2007;85:9-18.

[10] Redek B, Gordan C S Smith, Fergal D M, Robert H B, David A N, Christine H C et all. Fetal growth in early pregnancy and risk of delivery of low birth weight infant: Prospective cohort Study. B M J 2007 April 21;334(7598):836.

[11] Finch B K. Socioeconomic gradients and low birth weight: empirical and policy considerations. Health Serv Res 2003;38:1849-51.

[12] Wan X, Ding H, Ryan L. Association between air pollution and LBW: a community based. Environ Health Perspect 1997; 105:514-20.

[13] D. Da Costa, M. Dritsa, J. Larouche, W. Brender. 'Psychological predictors of labor \delivery complications and infant birthweight: a prospective multivariate study.' Journal of Psycholosomatic, Obstetrics and Gynaecology 2000, Vol 21(3):137-48.

[14] Hiremath DA, Hiremath D Lalita. Essentials of Community Medicine- A practical approach. New Delhi, Jaypee Brothers 2004:13.

[15] Kavitha Balaji, Sathish Sankar, Balaji Nandgopal. Low Birth Weight of Newborns: Magnitude of the Problem Seen in a 100 Bed Hospital of a Rural Area in Vellore District, Tamil Nadu (India).Indian J Com Med April 2010,35(2):362-64.

[16] K. S. Negi, S. D.Kandpal, M Kukreti. Epidemiological factors affecting Low Birth Weight. J K Science Jan-Mar 2006;8(1):31-4.

[17] S. Kayastha, H. Tuladhar. A Study of LBW babies in Nepal Medical College. Nepal Med College J Dec 2007; 10(2):266-9.

[18] Mariam Vah daninia, Sedigheh S Tavafian, Ali Montazeri. Correlates of low birth weight in term pregnancies: a retrospective study from Iran. BMC Pregnancy and Childbirth 2008,8:12.

[19] Dinh PH, ToTH, Yuong TH, Hojer B, Persson LA. Maternal factors influencing the occurrence of low birth weight in northern Vietnam. Ann Trop Paediatr 1996 Dec;16(4):327-33.

[20] Sareer BadShah, Linda Mason, Kenneth Mekelvie, Roger Payne, Paulo JG Lisbia. BMC Public Health $2008,8: 197$.

[21] Hirve SS, Ganatra BR. Determinants of low birth weight: a community based prospective cohort study. Indian Pediatr Oct 1994,31(10):1221-5.

[22] Kiran Anand, B. S. Garg. A Study of factors affecting LBW. Indian J Com Med 2000;25(2):57-62.

[23] Mavalankar DV, Gray RH, Trivedi CR. Risk factors for preterm and term low birth weight in Ahmedabad, India. Int J Epidemiol April 1992;21(2):263-72.

[24] Deshpande Jayant D, Phalke DB, Bangal V B, D Peeyuusha, Bhatt Sushen . Maternal risk factors for LBW Neonates: A Hospital based case control study in Rural Area of Western Maharashtra,India. National Journal of Com Med Oct-Dec 2011;2(3):394-98

[25] Joshi HS, Srivastava PC, Agnihotri AK ,Joshi MC, Chandra Shalini, Mahajan Vipul Risk factor for LBW Babies and its Medicolegal Significance. J Indian Acad Forensic Med Jan-Dec 2006;32(3):212-17.

[26] Panaretto K, Lee H, Mitchell M, Larkins S, Manessis V, Buett ner P, Watson D. Risk factors for preterm lowbirth weigh t and small for gestational age birth in urban Aboriginal and Torres Strait Islands' Women in Townsville. Aust N Z J Public Health Apr 2006;30(2): 163-70.

[27] S. A. Rizvi, J Hatcher, I. Jehan, R. Qureshi. Maternal risk factors associated with Low birth Weight in Karachi: a case -control study. Eastern Mediterranean Health Journal Nov-Dec 2007;13(6):1343-52. 